\title{
Desafios e descompassos de uma cidade rumo à indústria criativa
}

\author{
Challenges and imbalances of a city towards the creative industry
}

\begin{abstract}
Aline Maria Grego Lins - Universidade Católica de Pernambuco I Recife I PE I Brasil I aligrego@uol.com.br () 0000-0001-7905-8376

Maria Júlia Queiroga - Universidade Católica de Pernambuco I Recife I PE I Brasil I m.juliaqueiroga@gmail.com (1) 0000-0003-3819-9855
\end{abstract}

Resumo: Este trabalho visa mapear o cenário econômico e cultural da cidade do Recife, no século $X X$, com o objetivo de identificar iniciativas que contribuem para a indústria criativa da cidade hoje. Ao longo de sua existência, a capital pernambucana foi marcada por experiências culturais significativas, nas áreas do cinema e da tecnologia da informação. A pesquisa parte do pressuposto de que essas experiências contribuíram para a vocação criativa empreendedora da cidade e para o surgimento, no final do século, do Porto Digital. O presente artigo é resultante de uma pesquisa, de caráter exploratório, que optou pelo resgate histórico realizado a partir de fontes documentais, entre elas, documentos oficiais, institucionais e publicações jornalísticas de diferentes suportes, tais como produtos digitais.

Palavras-chave: Recife. Porto digital. Indústria. Economia criativa.

Abstract: This work aims to map the economic and cultural scenario of the city of Recife in the 20th century with the objective of identifying initiatives that contribute to the city's creative industry today. Throughout its existence, the state of Pernambuco was marked by significant cultural experiences in the fields of cinema and information technology. The research is based on the assumption that these experiences contributed to the city's creative entrepreneurial vocation, and to the emergence, at the end of the century, of the Digital Port. This article is the result of an exploratory research that has opted for a historical rescue made from documentary sources, including official, institutional, and journalistic publications in different media, such as digital products.

Keywords: Recife. Digital port. Industry. Creative economy.

doi http://doi.org/10.22484/2318-5694.2019v7n14p53-73

Enviado em outubro 2018 - Aprovado em fevereiro 2019 


\section{Introdução}

Desde o final do século $X X$ e início do século $X X I$, a economia de Pernambuco, estado localizado na região Nordeste do País, tem se modificado profundamente. Uma das razões para essa transformação é a expansão da economia e da indústria criativa e do empreendedorismo, na região central da cidade, a exemplo da instalação do Porto Digital. Segundo o mapeamento das Indústrias Criativas, realizado pela Federação das Indústrias do Estado do Rio de Janeiro - FIRJAN, em 2013, o aumento em Pernambuco desse setor foi de 14\%. No Brasil, em 2014, comparado há dez anos anteriores, o setor aumentou 69,1\%.

O Porto Digital é uma organização não governamental, localizada no bairro do Recife Antigo, área central da cidade, e nos bairros vizinhos de Santo Amaro, Santo Antônio, São José e Boa Vista, que congrega empresas de inovação e tecnologia da informação e comunicação - TIC. O Porto foi instalado em 2000, com o objetivo de fomentar a economia criativa do estado. Em razão desse projeto, tanto essa região central da cidade quanto seu entorno vem sofrendo grande especulação imobiliária, em especial o bairro de São José, que praticamente fica entre o Recife Antigo e o bairro do Pina, área litoral, que nos últimos dez anos foi palco de aceleradas construções residenciais de alto padrão e empreendimentos empresarias do mesmo nível, inclusive um grande centro de lojas, modificando o perfil social do lugar. O bairro do Pina, que antes era formado por casas simples de único andar, e uma população igualmente simples, muitos pescadores ou descendentes deles, hoje é o metro quadrado mais caro do Recife (a área que fica em frente ao mar) e uma das regiões mais valorizadas da cidade.

Um caso emblemático desse cenário especulativo vivenciado pela cidade, só arrefecido este ano em razão da grave crise econômica enfrentada pelo país, foi o Cais José Estelita, espaço urbano de vista 
privilegiada para a Bacia do Pina (encontro do mar com o rio), onde existiam armazéns do antigo Instituto do Álcool e do Açúcar - IAA, pertencentes à União, que desencadeou uma forte reação popular frente à decisão governamental de ceder os terrenos, onde estão esses armazéns abandonados, às empreiteiras privadas, a preços bem abaixo do mercado. O projeto das construtoras era tão somente construir imóveis empresariais e residenciais de alto custo, em detrimento do atendimento à população mais carente e que há anos ocupa o mesmo espaço, e sem levar em consideração, também, a abertura de espaços públicos, a exemplo de praças e/ou jardins para a população da cidade de um modo geral.

As mudanças porque passam os centros urbanos brasileiros, entre eles, o da cidade do Recife, parecem ainda dar as costas para os que povoam e resistem em habitar nessa região, tal como já havia ocorrido no início do século XX.

\begin{abstract}
Apesar da evasão provocada pelas obras de 100 anos atrás, o bairro do Recife ainda abriga moradias. Assim como no início do século $\mathrm{XX}$, muitos trabalham e moram nas ruas em condições de precariedade contínua. Como antes, essa parcela da população presta pequenos serviços e convive com a condição de invisibilidade e vulnerabilidade social. A retomada do bairro do Recife como ponto turístico nos anos 2000 e a atual consolidação como referência de parque tecnológico, centro de consumo e entrada da cidade (graças às mais recentes obras requalificação e reurbanização de áreas usadas para operação portuária) não alterou o cenário do trabalho e da moradia precarizada do local. (PINTO, 2015).
\end{abstract}

Contrastes e contradições que estão na direção contrária ao que se propõe o Porto Digital, pensado para valorizar a região central da cidade e ser um polo gerador de inovações e de trabalho para a população interessada nas atividades da indústria criativa, inclusive na formação e capacitação dessas pessoas. 
O objetivo deste artigo é procurar identificar no percurso da economia criativa que está sendo traçado no Recife, em especial a partir do Porto Digital e seu braço criativo, o Portomídia, eventos e/ou ações que no século $\mathrm{XX}$ possam ter influenciado as áreas escolhidas para atuação desse Porto. Considerando que são muitos os eventos no século passado, este artigo opta por um recorte, partindo do pressuposto que a existência da veia criativa do povo recifense é flagrada em algumas experiências da cidade envolvendo o cinema e, mais para o final do século, a Tecnologia da Informação e Comunicação (TIC). Essas iniciativas vão ser observadas como prenúncio de atividades integrantes das denominadas indústria e economia criativas, que contribuem para o surgimento de ambientes propícios a ações empreendedoras que, a princípio, devem estar comprometidas com a sustentabilidade econômica e social da cidade.

A primeira etapa da pesquisa, que originou esse artigo, foi fazer 0 mapeamento dos primeiros passos de iniciativas criativas no Recife, na área do audiovisual, que ocorreram em décadas anteriores aos conceitos cunhados por estudiosos australianos e ingleses, nos anos de 1990, sobre indústria e economia criativas.

A indústria criativa difere dos modelos administrativos do Taylorismo e do Fordismo, que tiveram espaço e força no século anterior, uma vez que as "pessoas que detêm ideias se tornaram mais poderosas do que aquelas que operam máquinas e, em muitos casos, até mais do que aquelas que possuem máquinas" (HOWKINS, 2013, p. 13). Segundo o Relatório Especial sobre Economia Criativa, elaborado pela Organização das Nações Unidas para a Educação, a Ciência e a Cultura $^{1}$ (UNESCO) e pelo Programa das Nações Unidas para o Desenvolvimento (PNUD), em 2013, a economia criativa tornou-se uma força transformadora, em especial para países emergentes como o Brasil.

\footnotetext{
${ }^{1}$ Published by the United Nations Development Programme (UNDP), One United Nations Plaza, New York, NY 10017, USA and the United Nations Educational, Scientific and Cultural Organization (UNESCO), 7, place de Fontenoy, 75352 Paris 07 SP, France -ISBN 978-92-3-001211-3.
} 
Face à multiplicidade de conceitos disponíveis na literatura especializada sobre indústria/economia criativa, entende-se como necessário destacar que trabalhamos o conceito de indústrias criativas na perspectiva daquelas que:

produzem bens e serviços que utilizam imagens, textos e símbolos como meio. São indústrias guiadas por um regime de propriedade intelectual e [...] empurram a fronteira tecnológica das novas tecnologias da informação. Em geral, existe uma espécie de acordo que as indústrias criativas têm um core-group, um coração, que seria composto de música, audiovisual, multimídia, software, broadcasting e todos os processos de editorial em geral (JAGUARIBE, 2006 apud BENDASSOLLI et al., 2009, p. 12, grifos do autor).

Estratégias narrativas, processos de elaboração e circulação de produtos da indústria criativa, com ênfase em ambientes de convergência midiática, estão entre os focos de interesse tanto dessa indústria quanto da economia criativa e dos estudos de comunicação, sobretudo na relação com as tecnologias da informação. A interface entre esses saberes manifesta-se na construção de discursos e efeitos de sentido nas diversas plataformas tecnológicas ou experiências empreendedoras, a exemplo do que hoje acontece no Portomídia, não apenas de forma virtualizada, mas também na forma física que esse espaço ocupa.

\section{Economia e indústria criativas}

De acordo com o mapeamento realizado no Brasil pela FIRJAN Federação das Indústrias do Estado do Rio de Janeiro (2014), a economia criativa possui quarto núcleos: Consumo, Cultura, Mídia e Tecnologia. A área de Consumo abrange publicidade, arquitetura, design e moda. Cultura engloba expressões culturais, patrimônios, música e artes cênicas. Em Mídia, destaque para o audiovisual e o editorial, enquanto que na área da 
Tecnologia estão presentes a Pesquisa e Desenvolvimento (P\&D), Biotecnologia e a Tecnologia da Informação e Comunicação (TIC).

A economia criativa representa um novo modelo de negócio, pois sua produção e geração de serviços e produtos resultam do conhecimento, da inovação e da criatividade, sendo esta última considerada a matéria prima e fundamental das indústrias que interferem nessa economia. Todavia, alerta Howkins (2013, p. 39), "a criatividade por si só não tem valor econômico. Ela precisa ser plasmada em um produto comercializável se quiser alcançar valor comercial". E complementa que para esse novo sistema expandir, os governos a partir das políticas públicas precisam "incentivar a criatividade, o desenvolvimento intelectual e criar um ecossistema favorável" (p. 39).

Nesse sentido, o apoio dos governos, por meio de fomento, aos setores criativos, tornam-se fundamentais, tal como ocorreu, por exemplo, na Inglaterra, nos anos 90, durante o governo do Tony Blair. No Brasil, as ações nesse sentido são consideradas ainda tímidas. Segundo pesquisa do IPEA, a economia criativa brasileira, em 2013, variava entre 1,2\% e $2 \%$ do PIB nacional. Esse cenário, quando comparado ao de outros países, revelou que o Brasil estava bem abaixo dos países onde as indústrias criativas são expressivas, a exemplo da França e da Inglaterra. No caso do Reino Unido, no final dos anos 90, não só foi desencadeado o apoio às indústrias e, consequentemente, à economia criativa, mas se reconheceu nas indústrias criativas, além do quesito criatividade, um grande potencial para a geração de empregos, a partir da exploração da propriedade intelectual, bem como a capacidade para produzir riqueza, justamente ao reunir habilidades e competências dos recursos humanos envolvidos nesse tipo de indústria (OLIVEIRA; ARAúJO; SILVA, 2013).

No Brasil, essas iniciativas e apoio governamentais, inclusive da União, estão concentrados ainda, de acordo com o mapeamento da economia criativa atualizado em 2016 pela Federação das Indústrias do 
Estado do Rio de Janeiro - Firjan, nos estados de São Paulo e Rio de Janeiro. Os dois estados são os que respondem, também, pela maior participação de trabalhadores formais na área da criatividade: 2,4\% em São Paulo e $2,2 \%$ no Rio de Janeiro. Tentando quebrar essas desigualdades econômicas, alguns estados da região Nordeste do país começaram a empreender ações voltadas para a indústria criativa, no início deste século XXI, a maioria em centros urbanos, a exemplo do Recife, onde foi instituído, em 2002, por governos locais, o Fundo de Incentivo à Cultura Funcultura, que passou a ser uma referência para os que atuam, sobretudo, no audiovisual e na inovação tecnológica. Ainda assim, são experiências tímidas, se levado em conta o potencial criativo da cidade e do próprio estado em outras áreas, tais como a música, o artesanato, o design e a fotografia.

\section{Recife no século XX - economia e cultura}

Até a chegada do século $X X$, a economia de Pernambuco era basicamente centrada na produção açucareira, mas a atividade enfrentou várias crises, provocadas pela oscilação do preço do açúcar no mercado externo e pela estagnação do setor na própria região, que não se modernizava na velocidade que as demandas econômicas e, principalmente as sociais, demandavam. Nesse mesmo período, Pernambuco, particularmente o Recife, experimentou outros arranjos industriais, a exemplo da produção têxtil. Segundo Bruno Andrade (2016), o Censo de 1907 apontava que "o capital social das fábricas de tecido em Pernambuco era superior àquele empregado na Bahia", até então era considerado o principal produtor têxtil do Nordeste ${ }^{2}$. (p.15)

\footnotetext{
${ }^{2}$ Esse setor também experimentou, assim como todo o país, as graves crises econômicas das décadas de 1970 e 80, várias fábricas foram fechadas e seus espaços foram transformados em centros de lojas ou em condomínios residenciais. Hoje, a produção têxtil continua presente em Pernambuco, mas agora deslocada para as cidades do interior, em especial da região do Agreste, a exemplo de Caruaru, Toritama e Santa Cruz do Capibaribe.
} 
Outras iniciativas da capital pernambucana no século passado foram vivenciadas no campo da cultura, a exemplo das artes plásticas, música e da inovadora experiência cinematográfica. Será esta última que aqui passaremos a destacar. Nos anos de 1920, o Recife foi palco do empreendedorismo no cinema. Hoje, esse feito é considerado pelos estudiosos da área como sendo um dos Ciclos Regionais de Cinema mais importantes que aconteceu no país. Em apenas oito anos, tempo que durou a experiência do cinema não falado na cidade, foram produzidos 13 longasmetragens de ficção e dezenas de documentários, todos roteirizados, filmados, montados e exibidos na cidade. Parte desse acervo - em especial os filmes de longa-metragem - encontra-se hoje, decorridos quase 100 anos, conservado, devidamente catalogado e sob a guarda da Fundação Joaquim Nabuco - FUNDAJ (2017).

Entre 1923 e 193133, o Ciclo do Recife produziu 13 filmes de ficção e mais dezenas de documentários, além de filmes que ficaram inacabados (fiç̧ão). Alguns nomes desse período se destacaram entre diretores, roteiristas, produtores e atores, entre eles, Edson Chagas, Gentil Roiz, Jota Soares, Pedro Salgado Filho, Antônio Campos, Rilda Fernandes, Almery Esteves, Oséias Torres de Lima, Tancredo Seabra, Ari Severo, Luís Maranhão, entre outros (FIGUEIROA, 1994). Segundo o professor e pesquisador Paulo Cunha Filho (2006, p. 7), eram cerca de 30 jovens, das mais diferentes profissões e origem social, que "mesmo enfrentando dificuldades, que - iam desde a revelação da película até a exibição e distribuição dos filmes", e apesar das precariedades técnicas e financeiras, ainda assim, chegaram a criar nesse período nove produtoras - diferentes e rivais (abrir firmas como se dizia na época).

Apesar da produção considerada significativa para a época, o processo de concepção e execução dos filmes carregavam certo

\footnotetext{
${ }^{3}$ Não há consenso sobre o período de vida do Ciclo do Recife, uma vez que há pesquisadores que reconhecem o Ciclo só até o período das produções dos filmes e outros que consideram até o período de suas exibições.
} 
amadorismo, sobretudo no quesito gestão, comparado ao profissionalismo dos filmes de Hollywood, que já nesse período, a exemplo dos dias atuais, invadiam as salas de cinema brasileiras. Ainda assim, jornais da época registram que os filmes atraiam um público interessado nas imagens em movimento, o que viria a tornar-se uma das paixões da cidade. Para se ter uma ideia da semente plantada pelo Ciclo Regional do Cinema do Recife, há 21 anos a cidade promove o Festival de Cinema que reúne o maior público entre os festivais nacionais, o Cine PE - Festival Audiovisual, também conhecido como Festival de Cinema do Recife.

Nas décadas de 1970 e 1980, a cidade volta a respirar a produção cinematográfica, desta feita, com o Movimento Super 8, com o uso filme de $8 \mathrm{~mm}$ e as possibilidades de mobilidade e manuseio promovida pela câmera Super 8. Não tardou para que um grupo de jovens, entusiasmado com os custos do equipamento e de seu filme se animassem a produzir filmes experimentais. Mas o curioso é que antes deles, um veterano no cinema, Firmo Neto, realizador do primeiro filme falado em Pernambuco, "O Coelho Sai", resolve deixar o $16 \mathrm{~mm}$ e a passar a trabalhar com o Super 8, identificando vantagens do baixo custo. De toda forma, os filmes produzidos pela safra do Super 8 foram mais domésticos e experimentais, em que os cineastas arcavam com os custos da filmagem e da revelação, o que ocorria de forma caseira (NOGUEIRA, 2009). Nessa época, ainda não existiam cursos no estado de Pernambuco que formassem pessoas para atuar no cinema, de modo que a maioria dos superoitistas era de estudantes de artes e de jornalismo, jornalistas e alguns profissionais que tinham incursões na fotografia. Ainda assim, o Super 8 acabou servindo como escola para a geração que começaria a despontar no final do século XX.

Na segunda metade de 1990 do século passado, o audiovisual, mais uma vez, volta a destacar-se na cidade com a denominada Retomada do Cinema Pernambucano, tendo como marco o filme Baile Perfumado, de Lírio 
Ferreira e Paulo Caldas, vencedor do Festival de Cinema de Brasília de 1996, na categoria melhor filme.

Mas, além do audiovisual, outra atividade começa a despontar no Recife no final do século passado, a tecnologia da informação. Esse setor iria protagonizar mudanças na região central da cidade e na "economia cultural" pernambucana. Os primeiros passos, em 1996, foram dados pelo Centro de Estudos e Sistemas Avançados do Recife (C.E.S.A.R), um empreendimento liderado por professores da Universidade Federal de Pernambuco, que contribuiu para um novo olhar sobre a economia do estado e da cidade. Além de provocar, junto aos governos locais, ações que pudessem recuperar urbanisticamente o bairro histórico do Recife Antigo, região portuária central da cidade, que viu o Recife nascer.

\section{Bairro do Recife Antigo - centro da capital pernambucana}

O bairro do Recife era a entrada principal de Pernambuco, em razão da presença do Porto de embarque e desembarque de mercadorias e viajantes. Essa região, onde está cravado o bairro, passou por três grandes mudanças urbanísticas, sendo a primeira durante o período da invasão holandesa (1630-1654), com a construção da Ponte Maurício de Nassau, que passou a ligar o Recife Antigo a outras ilhas, iniciando o processo de expansão para o continente e a série de modificações que ocorreriam em sua estrutura para abrigar os novos rumos da cidade. Contudo, as mudanças arquitetônicas mais significativas aconteceram no século XIX e, principalmente, já nas primeiras décadas do século $X X$, quando houve a urbanização desses espaços mais centrais da capital pernambucana, justificada, à época, pelo movimento sanitarista que tomou conta das principais cidades brasileiras, liderada pela então capital federal, Rio de Janeiro, mas que trazia em seu bojo os interesses com a infraestrutura dos portos, e a expansão comercial. No caso do movimento de higienização, o 
objetivo era combater as graves epidemias que assolavam as cidades, fruto da ausência de ações sanitárias, e de modo especial, erradicar os focos de epidemias que proliferavam nas regiões portuárias a exemplo do Recife e do Rio de Janeiro (LUBAMBO, 1991; SETTE, 1978).

Aliado a esse cenário, havia o pretexto e interesse em modernizar as regiões centrais, sobretudo nas quatro primeiras décadas do século $X X$, que já experimentavam as ações da especulação imobiliária impulsionadas pelos novos adventos e invenções, a exemplo do automóvel e da indústria têxtil, que já citamos neste artigo. O planejamento urbano da região central do Recife, segundo Joel Outtes além de apresentar uma visão tecnocrática e autoritária, foi responsável por outra marcante característica do período, a exclusão social. "Com efeito, não houve participação alguma de setores populares e de representação dos trabalhadores na discussão sobre a cidade à época" (OUTTES, 1997, p. 215). Migraram para essa região as sedes das principais empresas e importação e exportação, bem como os serviços financeiros atrelados a esse setor, a exemplo de bancos oficiais e privados e a Bolsa de Valores do estado. Pode-se dizer que os anos de 1940 e 1950 foram os que o bairro do Recife experimentou os maiores progressos e também riqueza.

Contudo, na segunda metade do século XX, principalmente a partir dos anos de 1960, o Recife Antigo foi entregue a própria sorte, esquecido em razão da expansão da cidade para outras regiões, sobretudo os bairros mais próximos ao continente, em que estavam contempladas as praias de Pina e Boa Viagem, na zona sul da cidade, ou aquelas áreas que, em razão da proximidade do rio Capibaribe e da preservação de matas e jardins, apresentavam clima mais ameno e dessa forma atraiam a população, casos dos bairros de Parnamirim e Casa Forte. O fato é que até a década de 1980, o Recife Antigo experimentava o abandono, com um conjunto histórico arquitetônico depredado e a zona portuária esvaziada, em razão das mudanças que começavam a acontecer do Porto do Recife para o Porto de 
Suape, o novo porto do estado, mais moderno e localizado entre os municípios do Cabo de Santo Agostinho e Ipojuca, ambos na Região Metropolitana da cidade.

Só no final da década de 1980 é que as atenções se voltam novamente para o Recife Antigo, motivado pelo surgimento do Plano de Revitalização do Bairro do Recife- PRBR, que fazia parte do Programa Integrado de Desenvolvimento do Turismo no Nordeste - PRODETUR, elaborado a partir de estudos encomendados pelo Banco Nacional de Desenvolvimento Econômico e Social (BNDS).

O Programa teve por objetivo revitalizar as áreas urbanas históricas do país, entre elas, a do bairro onde nasceu o Recife, a cidade com status de capital mais antiga do Brasil, que completou, em 2018, 481 anos de existência. O Plano de Revitalização, que passou a ser efetivamente implantado nos anos de 1990 com recursos que envolveram as iniciativas pública e privada, segundo Zancheti e Lacerda (1999, p. 23), revelou que a estratégia incorporada por esses agentes, a partir de projetos de revitalização "formulados com clareza de objetivos, em áreas de grande significado simbólico para a população local e conduzidos por lideranças legítimas", produziu "resultados significativos quanto à abertura de uma nova rota de desenvolvimento econômico". Entre esses agentes, estava o Porto Digital, já citado neste artigo e que abordaremos mais à frente.

O final do século XX revelou, ainda, que o Recife possuía um ecossistema propício para a formação intelectual e profissional de pessoas na área da Tecnologia da Informação. Antes da instalação do Porto Digital, a cidade já possuía um mercado em expansão, com a presença da IBM e Borges, além de bancos e empresas locais - a exemplo do Banorte (banco) e Bompreço, na área de varejo, que possuíam setores de T.I bem desenvolvidos para a época no país.

$\mathrm{Na}$ área acadêmica, existia o Centro de Tecnologia da Informação da cidade, criado na Universidade Federal de Pernambuco (UFPE), em 1974, 
no Departamento de Estatística e Informática. Na época, a formação oferecida era o bacharelado e a pós-graduação em Ciência da Computação. Em 1999, o Departamento de informática alcança o status de Centro e passa a ser o Centro de Informática (UFPE, 2017).

$\mathrm{Na}$ Universidade Católica de Pernambuco (Unicap), destaca-se o Núcleo de Informática (NIC), que formava técnicos em nível pós-médio para o setor. Segundo Francisco Saboya Albuquerque Neto ${ }^{4}$, ex-presidente do Porto Digital, a expertise dos profissionais mais maduros, da década de 60 e 70, oriundos do mercado, passou a ser reforçada pelos recém-formados por essas instituições, que apresentavam uma bagagem teórica mais sofisticada.

Esse foi, desde então, o papel das universidades, proporcionar uma formação focada nas novas demandas, que acabaram por promover mudanças no mercado não só de T.I, mas de tecnologia de um modo geral, entre eles o da comunicação. As empresas locais passaram a se expandir, contribuindo para a retenção dos profissionais na cidade, entre essas novas atividades estava à produção de games. Os primeiros estudos de games ocorreram com a oferta de uma disciplina, em 2000, na UFPE, para atender a demanda de uma empresa local, a "Arte Vudu", que precisava de pessoas conhecedoras do processo de desenvolvimento de jogos. Depois foi a vez de a Unicap lançar, em 2010, o primeiro curso Superior Tecnológico em Jogos Digitais do estado, que de acordo com Anthony Lins ${ }^{5}$ trouxe novas oportunidades de trabalho e qualificação para um grupo muito jovem de profissionais, focado na indústria criativa.

\footnotetext{
${ }^{4}$ Entrevista com Francisco Saboya, ex-presidente do Porto Digital, realizada por Aline Maria Grego Lins e Maria Júlia Queiroga, em dia 20 de abril de 2017, no Recife, Pernambuco, Brasil, como parte de pesquisa intitulada " $\mathrm{O}$ Percurso das Indústrias Criativas no Recife: resgate histórico e desafios para o futuro".

${ }^{5}$ Entrevista com Anthony Lins, professor e coordenador do curso de Jogos Digitais da Universidade Católica de Pernambuco, realizada por Aline Maria Grego Lins e Maria Júlia Queiroga no dia 10 de janeiro de 2017, no Recife.
} 


\section{O Porto Digital: ecossistema para TIC e Economia Criativa}

O Porto Digital é um parque tecnológico cravado no bairro do Recife Antigo, que atua nas áreas de Tecnologia da Informação e Comunicação e, mais recentemente, em Economia Criativa. Ele foi concebido quando um grupo de professores da UFPE, liderados por Silvio Meira, percebeu que a maioria dos estudantes formados em Tecnologia da Informação da instituição não ficava no estado. De acordo com Saboya (2017), uma turma do mestrado de Informática da UFPE de 1993, formada por 17 alunos, foi contratada para trabalhar em empresas fora do Brasil, a exemplo da Microsoft. Reter esses estudantes no Recife e no país era o grande desafio. Em 1996, buscando modificar esse cenário, os professores universitários resolveram criar o Centro de Estudos e Sistemas Avançados do Recife (C.E.S.A.R) e o Instituto de Ciência e Tecnologia (ITC), destinados a desenvolver soluções complexas de T.I. Diversas empresas, logo de início, se interessaram em trabalhar com o C.E.S.A.R motivadas, certamente, pela lei da informática, a Lei n8.248/91 (BRASIL,1991), que propiciava incentivos fiscais às empresas do setor de tecnologia que investissem em pesquisa.

O Porto Digital é gerenciado por uma Organização Social (O.S), sem fins lucrativos e possui um núcleo de gestão - denominado Núcleo de Gestão do Porto Digital (NGPD), credenciado pelo Governo do Estado e pela Prefeitura da Cidade do Recife. É a ponte entre a sociedade civil, as universidades, o governo e as empresas. Segundo Francisco Saboya (2017) - que, após 11 anos, deixou a presidência do Porto, em 2018, mas continua a atuar na instituição - esse quadro contribui para que exista uma relação próxima entre o governo e o Núcleo, o que possibilita que acordos sejam efetivados mais rapidamente, dando velocidade aos processos. 
Em 2018, o Porto Digital abrigava 300 empresas e instituições ${ }^{6}$ instaladas, com cerca de 9.000 profissionais, mais de 800 deles empreendedores, e o conjunto de empresas é responsável por uma receita anual de cera um 1,7 bilhão. Engloba desde acessibilidade, inclusão e sustentabilidade até a área de produção cultural, games e multimídia. O Porto atua de forma especial, junto a empresas incubadas.

A opção por expandir-se na região central do Recife foi considerada estratégica por ter um grande fluxo de pessoas e serviços. Hoje, o Porto Digital, além de ocupar o Recife Antigo e alguns setores dos bairros de Santo Antônio e São José, expande-se também para o bairro da Boa Vista - uma região localizada também na região central da cidade, povoada por instituições de ensino e pesquisa, centros hospitalares, comércio variado e que abriga, ainda, muitas residências, portanto, também com fluxo intenso. É nesse ambiente que pesquisadores, empresários, governo e, sobretudo, micro empreendedores, trabalham visando a instituição de um cluster criativo. Nesse passo, um projeto do Porto Digital mostrou-se decisivo para o desenvolvimento do cluster - o Portomídia, pensado para capacitar, apoiar e incentivar empreendimentos próprios da indústria criativa, com destaque para as áreas que contemplem o audiovisual, a música, a fotografia e a produção de softwares.

\section{Portomídia e a Indústria Criativa}

Visando a expansão das atividades, os gestores do Porto Digital, a partir de 2008, passaram a trabalhar numa perspectiva para além da tecnologia da informação. Em 2010, a decisão foi apostar na economia criativa e o recorte utilizado priorizou atividades que envolvessem tecnologia da informação e da comunicação na interface com atividades

\footnotetext{
${ }^{6}$ Informações retiradas do Prospecto do Porto Digital, de 2016, cedido pela organização. Esse número costuma flutuar devido a empresas que encerram suas atividades.
} 
pertinentes as indústrias criativas. Compreendemos que as escolhas da fotografia, audiovisual (cine-vídeo-animação), música, design e games para compor o Portomídia, entre diversos segmentos existentes na indústria criativa (a literatura lista mais de dez segmentos), levou em consideração o histórico de algumas experiências criativas experimentadas na cidade, algumas já apontadas neste artigo, a exemplo do cinema e das atividades ligadas a TIC, bem como à percepção de que novos cursos de graduação, relacionados à indústria criativa, estavam sendo criados nas universidades pernambucanas e formando profissionais para essas áreas, a exemplo do curso de Cinema da UFPE (2008) e os cursos de Fotografia (2007) e Jogos Digitais (2007), ambos da Unicap, além do curso de Comunicação Social com ênfases em Mídias Sociais e Produção Cultural da UFPE, implantado em Caruaru (2013).

O Portomídia, por sua vez, além de ser espaço com estrutura e apoio para o empreendimento criativo, está voltado também para a formação profissional e para o desenvolvimento e experimentação de produtos criativos. Possui laboratórios de última geração já instalados, sobretudo na área do audiovisual, que permite trabalhos de pós-produção, inclusive alguns deles sendo utilizados pelos cineastas pernambucanos e de outros estados. O local é aberto a estudantes, produtores e empresas que desejam utilizar os equipamentos em suas pesquisas e projetos. Uma segunda fase das instalações dos laboratórios do Portomídia contemplará, entre outros segmentos, a música e a produção sonora de um modo geral, que já está em curso e será destinada a pré-produção, contando com a instalação de três núcleos de produção, teste e exibição.

Dentre os equipamentos que estão em funcionamento no Portomídia? , destaque para a ilha de correção de cor de filme e mixagem de som. $\mathrm{Na}$ área do empreendedorismo, seis startups graduadas e um empresa

\footnotetext{
${ }^{7}$ Até 2017 foram promovidos no Portomídia cerca de cem atividades, entre cursos, seminários e palestras (96), capacitando quase 2000 mil pessoas (1.950), todos explorando criatividade, inovação e tecnologia. Além disso, há no Portomídia uma galeria onde foram realizados mais de 40 eventos, em pouco mais de cinco anos.
} 
incubada. Em experimentação: 54 trabalhos de audiovisual, dois em games, nove em design, dois em fotografia, dois em interatividade e dois em música.

O Portomídia também está ampliando suas ações em direção ao interior do estado. Atualmente, possui uma extensão em Caruaru, município de Pernambuco, que fica a 200 quilômetros do Recife, conhecida por sua Arte Figurativa que teve origem nos trabalhos em barro do Mestre Vitalino e por ser hoje, também, um polo de confecção do agreste pernambucano. O objetivo é capacitar e apoiar empreendedores de indústrias criativas no interior do estado, focadas em moda e fotografia. O projeto foi batizado com o nome de Armazém da Criatividade e a meta é inovar com experiências nesses moldes em municípios pernambucanos.

\section{Considerações Finais}

Ao levar em consideração as experiências na área da Tecnologia da Informação e Comunicação e, em especial, as atividades das indústrias criativas da música, do audiovisual e dos games, a cidade do Recife, na confluência entre academia, iniciativa privada e pública, parece dar um importante passo rumo aos novos engendramentos produtivos para a cidade. É verdade, também, que muito há o que fazer, sobretudo nos quesitos sustentabilidade ambiental e social, uma vez que a capital pernambucana ainda guarda resquícios de políticas pouco inclusivas, ou raramente inclusivas - o caso do Cais José Estelita é um bom exemplo desse comportamento que precisa ainda ser revisito pelos gestores e moradores da cidade. Na pesquisa realizada até aqui é possível constatar nos documentos guardados em acervos públicos (jornais e filmes) que algumas atividades criativas na capital pernambucana surgiram de modo despretensioso, mas abriram caminhos para o que hoje está no foco das indústrias criativas, que pode vir a ser uma das alternativas de geração de 
empregos e de recursos para a população e para a cidade. O ciclo do Recife e o Movimento Super 8, estão nesses exemplos, bem como as iniciativas de TIC. Neste século XXI, as atividades e a produção criativa e de inovação que vem sendo empreendidas no Recife demonstram também a preocupação com a formação e qualificação de recursos humanos para essas áreas, cujo marco mais significativo está centrado nas universidades e no braço criativo do Porto Digital, o Portomídia. Recentemente, inclusive, passou a funcionar na Universidade Católica de Pernambuco o mestrado profissional em Indústrias Criativas. Esse ambiente criativo, unido ao trabalho criativo, ligado ou não as artes, podem ser flagrados como pontos de resistência culturais e pistas para saídas criativas para problemas e demandas econômicas e sociais para o Recife.

A pesquisa, ainda que parcialmente, aponta para o fato de que os eventos históricos, que marcaram a economia e as experiências da cidade do Recife, inspiraram novos projetos na passagem do século XX para o século XXI, a exemplo do já citado Porto Digital, mas também provocaram mudanças estruturais na urbanização de alguns bairros centrais da cidade, caso do Recife Antigo, e também nas relações e condições sociais dos que habitam nessas áreas. Se, por um lado essas experiência tem provocado um novo olhar para a capital pernambucana e suas potencialidades nas indústrias criativas, por outro ainda assistimos nas interferências, de modo especial, na arquitetura urbana e nos serviços que passam a oferecer, um descompasso entre o que precisa a população que reside na região central da cidade, e o que é dedicado e ofertado a população flutuante que usufrui das novas reconfigurações do bairro (turistas, residentes de outras regiões da cidade). Ainda assim, talvez não seja exagero dizer que os novos empreendimentos, a exemplo do C.E.S.A.R, Porto Digital e Portomídia são resultados do cenário de uma cidade que busca integrar cultura, arte, sustentabilidade e novas tecnologias numa perspectiva de sustentabilidade econômica e social. Mas, o que se percebe por enquanto, nos resultados 
parciais da pesquisa empreendida, é que se as perspectivas revelam-se promissoras para os empreendedores da indústria criativa, no quesito geração de recurso - do ponto de vista social está longe ainda de equacionar as distâncias e desequilíbrios entre oportunidades, geração de empregos e produção de riquezas para todos, e não apenas uma parcela da sociedade - assim, muito ainda há que se caminhar.

\section{Referências}

ANDRADE, Bruno Alves de. Distribuição espacial da indústria têxtil e de confecção em Pernambuco: qual a influência dos fatores locacionais. 2016. 74 f. Dissertação (Mestrado em Economia) Programa de Pós Graduação em Economia, Universidade Federal de Pernambuco, 2016.

BENDASSOLLI, Pedro F. et al. Indústrias criativas: definição, limites e possibilidades. Revista de Economia e Administração - RAE, São Paulo, v. 49, n. 1, p. 10-18, jan./mar. 2009. Disponível em: http://www.scielo.br/pdf/rae/v49n1/v49n1a03.pdf. Acesso em: 26 nov. 2015.

BRASIL. Lei no 8.248, de 23 de outubro de 1991. Dispõe sobre a capacitação e competitividade do setor de informática e automação, e dá outras providências. Diário Oficial [da] República Federativa do Brasil. Brasília, DF, 24 out. 1991. Disponível em: http://www.planalto.gov.br/ccivil_03/leis/L8248.htm. Acesso em: 16 abr. 2017.

CUNHA FILHO, P. (org.) Relembrando o Cinema Pernambucano: dos arquivos de Jota Soares. Recife: Massangana, 2006.

FEDERAÇÃO DAS INDÚSTRIAS DO ESTADO DO RIO DE JANEIRO - FIRJAN. Mapeamento da Indústria Criativa no Brasil. Rio de Janeiro, 2014. Disponível em: http://www.abradi.com.br/wpcontent/uploads/2015/05/Mapeamento-2014.pdf. Acesso em: 13 abr. 2017.

FEDERAÇÃO DAS INDÚSTRIAS DO ESTADO DO RIO DE JANEIRO FIRJAN. Mapeamento da Indústria Criativa no Brasil. Rio de Janeiro: Firjan, 2016. Disponível em: 


\section{tríade}

http://www.firjan.com.br/EconomiaCriativa/pages/default.aspx. Acesso em: 03 maio. 2017.

FIGUeirôA, Alexandre. O Cinema Super 8 em Pernambuco. Recife: Fundarpe, 1994.

FUNCULTURA. Breve histórico. Cultura PE: o portal da cultura pernambucana. Disponível em:

http://www.cultura.pe.gov.br/pagina/funcultura/sobre/breve-historico/. Acesso em: 11 jul. 2017.

FUNDAÇÃO JOAQUIM NABUCO - FUNDAJ. Disponível em: www.fundaj.gov.br. Acesso em: 25 abr. 2017

HOWKINS, John. Economia criativa: como ganhar dinheiro com ideias criativas. São Paulo: Makron Books, 2013.

LUBAMBO, Cátia W. O bairro do Recife: entre o Corpo Santo e o Marco Zero. Recife: CEPE/Fundação de Cultura da Cidade do Recife, 1991.

NOGUEIRA, Amanda Mansur Custódio. O novo ciclo do cinema em Pernambuco: a questão do estilo. 2009. 157 f. Dissertação (Mestrado em Comunicação) - Programa de Pós-Graduação em Comunicação, Universidade Federal de Pernambuco, 2009.

OLIVEIRA, João M.; ARAUJO, Bruno; SILVA, Leandro Valério. Panorama da economia criativa no Brasil. Rio de Janeiro: Instituto de Pesquisa Econômica Aplicada - IPEA, 2013.

OUTTES, Joel. O RECIFE: gênese do urbanismo 1927 - 1943. Recife: Fundaj; Massangana, 1997.

PINTO, Luiz Carlos. Bairro do Recife 100 anos depois: história de vencidos e esquecimento. Recife: Marco Zero Conteúdo, 2015. Disponível em: http://marcozero.org/bairro-do_recife-100-anos-depois/. Acesso em: 10 out./2018.

PORTO DIGITAL. Documentação técnica. Disponível em:

http://www.portodigital.org/parque/o-que-e-o-portodigital/documentacao. Acesso em: 10 set. 2018.

SABOYA, Francisco. [Palestra dia 15/03]. 2017. Conferência realizada na abertura do Programa de Pós-Graduação em Indústrias Criativas da Universidade Católica de Pernambuco, 15 mar. 2017. 
SETTE, Mário. Arruar - História pitoresca do Recife antigo. 3. ed. Recife: Secretaria de Educação e Cultura - Departamento de Cultura, 1978. Coleção Pernambucana.

UNESCO. United Nations Development Programme. Creative economy report: widening local development pathways. New York, 2013. Disponível em: http://www.unesco.org/culture/pdf/creative-economyreport-2013.pdf. Acesso em: 25 abr. 2017.

UNIVERSIDADE FEDERAL DE PERNAMBUCO. Centro de Informática. Sobre o CIn. Disponível em: http://www2.cin. ufpe.br/site/secao. php?s=1\&c=1. Acesso em: 25 abr. 2017.

ZANCHETI, Sílvio; LACERDA, Norma. A revitalização de áreas históricas como estratégia de desenvolvimento local: avaliação do caso do Bairro do Recife. Revista Econômica do Nordeste, Fortaleza, v. 30, n. 1, p 8-24, jan./mar. 1999. 